\title{
Optimization of culture conditions for mycelial growth and fruiting body production of naturally-occurring Philippine mushroom Lentinus swartzii Berk
}

\author{
Rich Milton R. Dulay ${ }^{1 *}$, Esperanza C. Cabrera ${ }^{2}$, Sofronio P. Kalaw ${ }^{1}$, Renato G. Reyes $^{1}$ \\ ${ }^{1}$ Center for Tropical Mushroom Research and Development, Department of Biological Sciences, College of Science, Central Luzon State University, Science City \\ of Muñoz, Nueva Ecija 3120 Philippines. \\ ${ }^{2}$ Department of Biology, College of Science, De La Salle University, Taft Avenue, Manila, Philippines.
}

\begin{tabular}{l}
\hline ARTICLE INFO \\
\hline Article history: \\
Received on: November 11, 2020 \\
Accepted on: March 08, 2021 \\
Available online: May 10, 2021
\end{tabular}

Key words:

Bio-efficiency,

Fruiting bodies,

Lentinus swartzii,

Philippine wild mushroom,

Secondary mycelia.

\begin{abstract}
Lentinus swartzii, belonging to Basidiomycota, is one of the unrecorded and un-utilized naturally-occurring mushrooms in the Philippines. With the intention to realize the full potential of this wild mushroom, the present work highlights the successful rescue, domestication, optimization of culture conditions (culture media, $\mathrm{pH}$, and physical factors) for mycelial growth, and evaluation of the fruiting body production on formulated substrate. The mycelia favorably grew on coconut water gulaman (CWG), potato sucrose gulaman (PSG), and potato dextrose agar. However, for practical and economic reasons, $\mathrm{CWG}$ was the basal medium used in the evaluation of $\mathrm{pH}$ and physical factors. The better-quality mycelial growth was obtained when cultured on $\mathrm{CWG}$ at $\mathrm{pH} 6$, and incubated in the dark, $30^{\circ} \mathrm{C}$, under sealed conditions. Both rice seeds and cracked corn were the most suitable materials for grain spawn production. Among substrate formulations, 7:3 ratio of rice straw and sawdust produced the highest mean weight of fruiting bodies ( $37.02 \mathrm{~g}$ per bag) and biological efficiency (7.40\%). Enriched cultivation of this mushroom by adding nutritious supplements in the substrate must be done in further studies.
\end{abstract}

\section{INTRODUCTION}

Mushrooms are naturally-occurring macrofungi usually found growing on lignin- and cellulose-rich substrates in both tropical and temperate conditions. Several mushroom species are considered nutritious and healthy food because of their unique umami taste and flavor, chemical compositions, and biological activities. They contain protein, carbohydrates, sugar, crude fiber, lipids, vitamins, minerals, polysaccharides, lipopolysaccharides, peptides, glycoproteins, nucleosides, triterpenoids, lectins, essential oil, fatty acids, anthraquinones, anthrones, tannins, flavonoids, phenols, alkaloids, steroids, and coumarins [1-3]. These important components of mushrooms could act as antimicrobial, antiviral, cardioprotective, hepatoprotective, chemopreventive, immune-modulatory, anticoagulant, anti-inflammatory, and anti-hypertensive [1,4]. Hence, mushrooms can be regarded as functional food.

In the Philippines, mushrooms have become one of the wellaccepted commodities among Filipinos and one of the priority

*Corresponding Author:

Rich Milton R. Dulay, Center for Tropical Mushroom Research and

Development, Department of Biological Sciences, College of Science, Central Luzon State University, Science City of Muñoz, Nueva Ecija 3120 Philippines.

E-mail: richmiltondulay@clsu.edu.ph crops for agricultural development of the government. However, to date, very few mushroom species are commercially cultivated including Pleurotus florida, Pleurotus sajor-caju, Pleurotus ostreatus, Pleurotus cystidiosus, Ganoderma lucidum, and Volvariella volvacea, despite the fact that the country has diverse macrofungal resources. Most of the wild mushrooms remain to be undiscovered and underutilized. Therefore, before their extinction, continuous collection of wild mushroom germplasms is necessary to increase the number of domesticated and cultivated mushrooms and to harness their full potential as sources of nutritious food and bioactive compounds for pharmacological purposes.

Lentinus swartzii (Polyporaceae) is one of the wild wood-rotting macrofungi that have not been reported from the Philippines. The fruiting bodies of this fungus have light-colored pileus with dense brown to black smooth scales and have leathery stipe, which grow singly or in cluster on deadwood. It has white spore print produced from the gilled underside of the pileus. In the past, the cultivation conditions of other Lentinus species, namely; Lentinus tigrinus, Lentinus sajorcaju, Lentinus squarrosulus, and Lentinus strigosus were optimized that lead to the development of their production technologies [5-9].

Aside from optimization studies, the chemical compositions and biological properties of these species were also established. L. tigrinus is rich in proteins, carbohydrates, fibers, minerals, and demonstrate 
hypoglycemic properties in alloxan-induced mice, embryotoxic and teratogenic effects in zebrafish, radical scavenging, and antibacterial activities [10-12]. L. strigosus, on the other hand, contains nutrients and mycochemicals (saponins, alkaloids, flavonoids, anthraquinones, anthrones, phenols, steroids, coumarins, and fatty acids) and demonstrates anti-oxidant and antibacterial activities [13]. Eguchi et al. [14] reported the anti-hypertensive activity of $L$. sajorcaju extract in spontaneously hypertensive rats. These important properties of Lentinus species indicate their significant roles in the nutraceutical and pharmaceutical industries.

To the best of our knowledge, there is no comprehensive report regarding growth optimization and property elucidation of $L$. swartzii; hence, this study was performed to understand the various factors influencing the growth and development. In our intention to domesticate, cultivate, develop production technology, and popularize the utilization of this wild mushroom, the culture conditions for mycelial growth and fruiting body production of $L$. swartzii were optimized with reference to the nutritional (culture media and $\mathrm{pH}$ ) and physical (aeration, illumination, and temperature) requirements for growth.

\section{MATERIALS AND METHODS}

\subsection{Mushroom}

Wild L. swartzii fruiting bodies growing on deadwood [Figure 1] were obtained from the Central Luzon State University Campus, Science City of Muñoz, Nueva Ecija, Philippines. The identity of the mushroom was previously confirmed using rDNA-ITS sequence analysis.

\subsection{Mushroom Culture Establishment}

Collected mushroom was brought to the laboratory for tissue culture [7]. Internal tissues were aseptically sliced and inoculated onto potato dextrose agar (PDA) plates using a flame sterilized inoculating needle. Culture plates were properly labeled and incubated at $30^{\circ} \mathrm{C}$ for 5-7 days to allow mycelial growth. Successful cultures were used as source of mycelial inoculant for the growth performance evaluation.

\subsection{Influence of Culture Media and $\mathrm{pH}$}

Four indigenous culture media, namely; rice bran sucrose (broth from $5 \% \mathrm{D} 1$ rice bran and 1\% sucrose) gulaman (local crude agar), corn grit sucrose (broth from $5 \%$ local yellow cracked corn and $1 \%$ sucrose) gulaman, coconut water (from mature coconut water) gulaman, and potato sucrose ( $25 \%$ potato cubes and $1 \%$ sucrose) gulaman and four commercially available culture media such as PDA, malt extract agar,

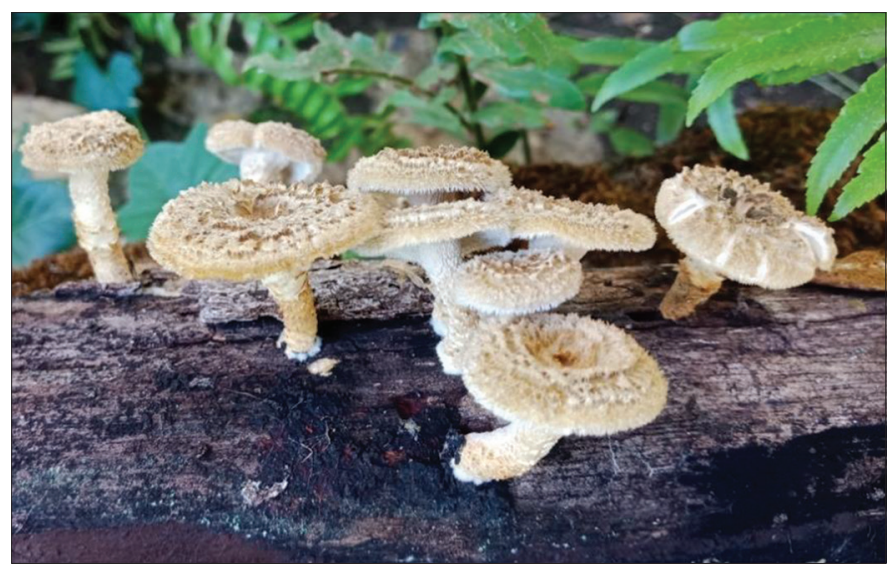

Figure 1: Wild fruiting bodies of Lentinus swartzii growing on deadwood.
Sabouraud dextrose agar (SDA), and mycological agar (MA) were evaluated in this study. Media were adjusted to $\mathrm{pH} 6$ and transferred into 1-L capacity flask plugged with cotton, wrapped with aluminum foil, and sterilized in an autoclave at $121^{\circ} \mathrm{C}, 15 \mathrm{psi}$ for $30 \mathrm{~min}$. Sterilized media were pour-plated, allowed to solidify, and inoculated centrally with 10-mm diameter mycelia discs from the 7-day old culture. The inoculated plates were sealed with parafilm and incubated at $30^{\circ} \mathrm{C}$ under alternating light and dark conditions. The diameter of mycelial growth was measured every $24 \mathrm{~h}$ until the full mycelial ramification and the mycelial density were recorded. Each treatment was replicated thrice. The best medium was used in the evaluation of the effect of $\mathrm{pH}$ in the medium. Medium was adjusted to different $\mathrm{pH}$ levels $(4.0,5.0,6.0,7.0,8.0$, and 9.0) using $1 \mathrm{M} \mathrm{NaOH}$ and $\mathrm{HCl}$. These were sterilized in an autoclave at $121^{\circ} \mathrm{C}$, 15 psi for $30 \mathrm{~min}$ and pour-plated. Plates were inoculated with mycelial disks and incubated at $30^{\circ} \mathrm{C}$. The mycelial growth diameter and mycelial density were determined to establish optimum $\mathrm{pH}$.

\subsection{Influence of Physical Factors}

The best medium and $\mathrm{pH}$ were used to determine the influence of illumination. Inoculated plates were incubated under artificial white light $\left(322.92\right.$ lumens $\left./ \mathrm{m}^{2}\right)$ and total dark, both at $30^{\circ} \mathrm{C}$. For temperature, culture plates were prepared and incubated in suitable illumination condition, and at different temperature conditions: $30^{\circ} \mathrm{C}, 20^{\circ} \mathrm{C}$, and $10^{\circ} \mathrm{C}$. Finally, for aeration, the inoculated plates were incubated in sealed and unsealed conditions. Cultures were incubated in the required illumination and temperature. Mycelial growth diameters and mycelial density were determined. All evaluations were done in triplicate.

\subsection{Evaluation of Grain Spawn Material}

Unmilled rice seeds, cracked corn seeds, and sorghum seeds were evaluated as spawn substrates for L. swartzii mycelia. Grains were boiled separately until tender, drained, and air-dried partially down to $65 \%$ moisture content. Twenty grams of grain were placed into each Petri plate. Each treatment was replicated 3 times. The plated grains were autoclaved at $121^{\circ} \mathrm{C}, 15 \mathrm{psi}$ for $45 \mathrm{~min}$ and allowed to cool. Grains were inoculated with $10 \mathrm{~mm}$-diameter mycelial disc and incubated at $30^{\circ} \mathrm{C}$. The growth diameter and mycelia density were recorded. The grain spawn with the fastest mycelia growth was the criterion used in choosing the best spawning material. The best grain spawn was mass produced and served as inoculant for fruiting body production.

\subsection{Evaluation of Fruiting Body Performance of $L$. swartzii on Formulated Substrate}

Rice straw and sawdust were used as the basal substrate and the different formulations were prepared following the formulations described by Dulay et al. [5]. Each formulated substrate (500 g) was compacted in a $6 \times 12$-inch mouthed polypropylene bag with cotton plug. Treatments were replicated 3 times. Bags were autoclaved at $121^{\circ} \mathrm{C}, 15$ psi for $1 \mathrm{~h}$ and allowed to cool. Grain spawn (40 g) were inoculated into each bag and subsequently incubated at $30^{\circ} \mathrm{C}$. The period for mycelia ramification and primordial initiation on the different formulations was determined. Fruiting bags were transferred in the growing house, opened, and watered to allow fruiting body development. Total fruiting body yield was recorded and the biological efficiency was calculated.

\subsection{Statistical Analysis}

Complete randomized design was used to lay-out all treatments. Data were analyzed using analysis of variance (ANOVA). Treatment means were compared using Tukey's HSD at 5\% level of significance in The 
SAS System Version 9.0 (SAS Institute Inc. Cary, NC, USA). T-test was used for the comparison of means with only two treatments.

\section{RESULTS AND DISCUSSION}

\subsection{Culture Media}

L. swartzii was tissue cultured and the pure culture of mycelia was successfully established. The culture was labeled as BIL4618. To determine the most favorable medium for the efficient mycelial growth of this mushroom, the effect of four indigenous culture media and four commercially available culture media was evaluated in this study. Figure 2 shows the mycelial growth diameter of L. swartzii

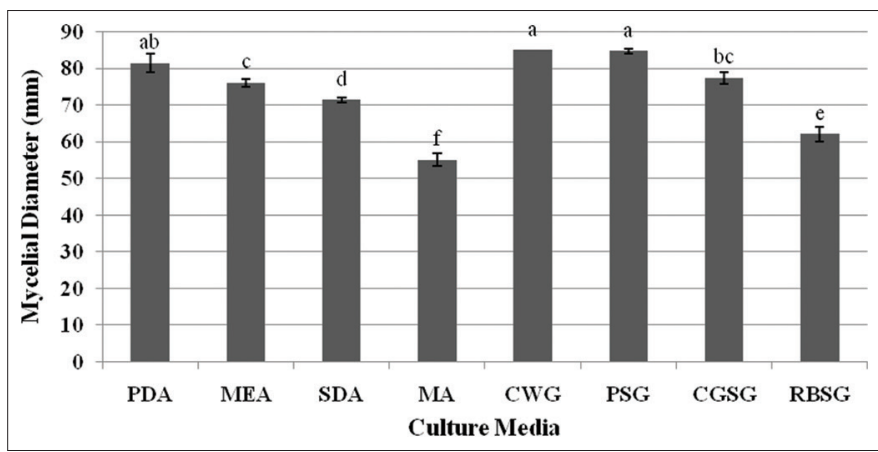

Figure 2: Mycelial growth diameter of Lentinus swartzii on the different culture media at $\mathrm{pH} 6$ in 4 days of incubation. PDA: Potato dextrose agar; MEA: Malt extract agar; SDA: Sabouraud dextrose agar; MA: Mycological agar; CWG: Coconut water gulaman; PSG: Potato sucrose gulaman;

CGSG: Corn grit sucrose gulaman; RBSG: Rice bran sucrose gulaman. Means with the same letters of superscript are not significantly different according to Tukey's HSD $(P<0.05)$.
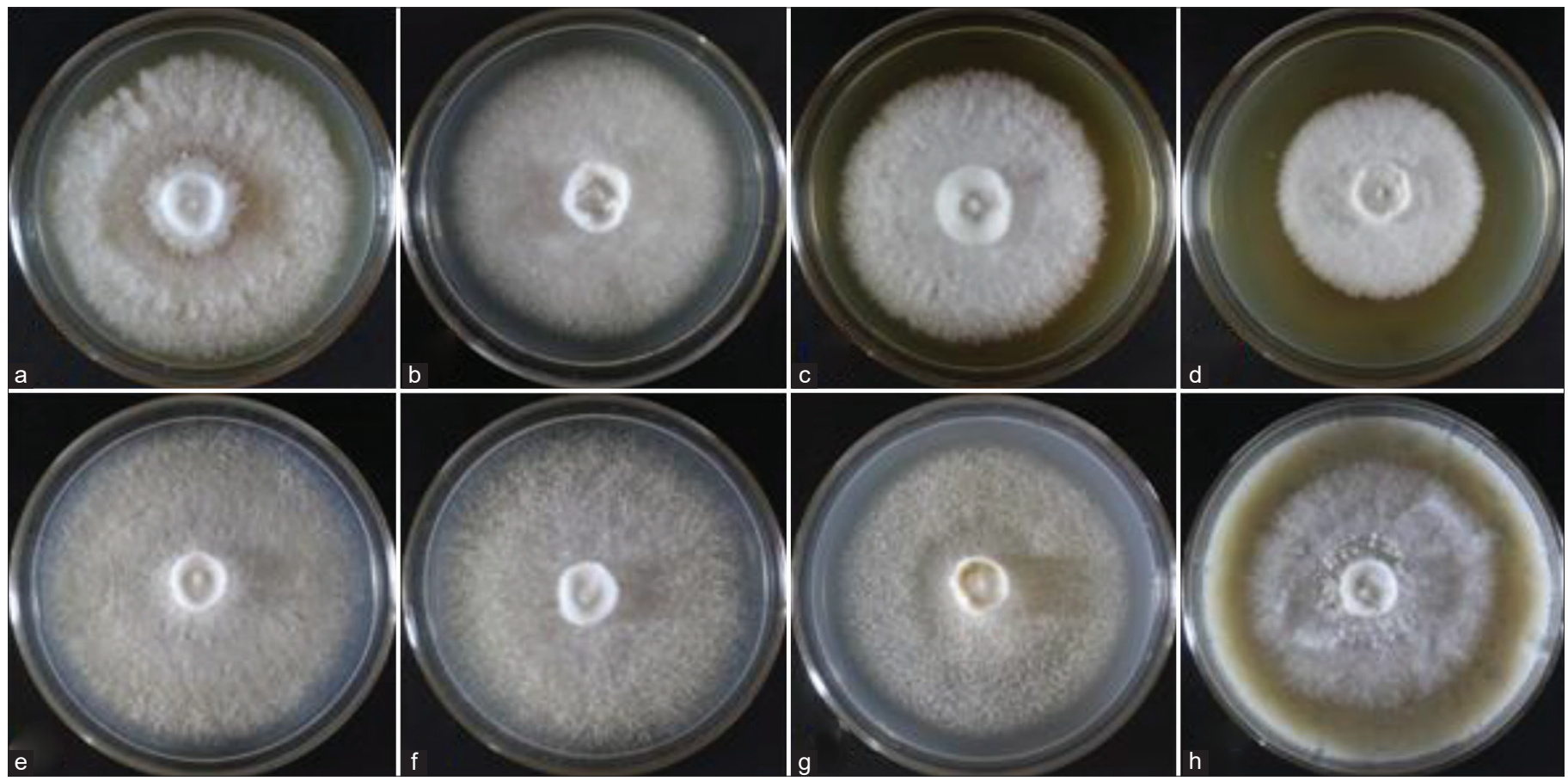

Figure 3: Mycelial growth of Lentinus swartzii on the different culture media: (a) PDA, potato dextrose agar; (b) MEA, malt extract agar; (c) SDA, Sabouraud dextrose agar; (d) MA, mycological agar; (e) CWG, coconut water gulaman; (f) PSG, potato sucrose gulaman; (g) CGSG, corn grit sucrose gulaman; and (h) RBSG, rice bran sucrose gulaman on the 4th day of incubation. 
10:1 promoted C. versicolor mycelial growth [21], whereas ratios of 10:1 and 5:1 supported Phellinus spp. mycelial growth [22]. Aside from the ratio, the nutrient sources are also important growth factors. Jo et al. [21] reported that the optimum carbon source for the growth of C. versicolor is dextrin, while the best nitrogen source is yeast extract. Kim et al. [23] found out that the most suitable carbon and nitrogen sources for the luxuriant growth of Oudemansiella radicata are xylose and alanine, respectively. Moreover, other components such as vitamins, organic acids, and minerals can also play important roles in the vegetative growth of mycelia. The addition of vitamins (thiamine$\mathrm{HCl}$ and biotin), organic acids (succinic acid, lactic acid, and citric acid), and mineral salt $\left(\mathrm{MgSO}_{4} \cdot 7 \mathrm{H}_{2} \mathrm{O}\right)$ produced excellent mycelial growth of $C$. versicolor [21]. Therefore, other than the screening of the suitable culture medium for mycelial growth, it is also necessary to evaluate the effect of composition ratio and nutrient sources on the growth of $L$. swartzii mycelia in future studies.

\subsection{Effect of $\mathrm{pH}$}

For practical and economical reasons, CWG was used as the basal medium in the evaluation of $\mathrm{pH}$ requirement of $L$. swartzii mycelia. In the present study, the effect of six pH levels of CWG on the mycelial growth of $L$. swartzii was determined. Noticeably, the favorable growth of $L$. swartzii was obtained in the range of $\mathrm{pH} 5-9$, but exceedingly favorable at $\mathrm{pH} 6$ [Figure 4]. All cultures produced thick mycelial growth [Figure 5]. This observation is in conformity with that of $L$. strigosus and $O$. radicata that could grow at a wide range of $\mathrm{pH}$, but their maximum mycelial growth was recorded at $\mathrm{pH} 6[6,23]$. However, the mycelia L. tigrinus grew best on $\mathrm{CWG}$ at $\mathrm{pH}$ 7-8 [5]. In liquid culture, the maximum mycelial biomasses of G. lucidum, P. cystidiosus, V. volvacea, and S. commune were obtained at $\mathrm{pH} 7,7,6$, and 8, respectively [24]. On the other hand, although lower mycelial growth diameter of L. swartzii was noted at $\mathrm{pH} 4$, it is interesting to note that the mycelia could favorably grow (as shown by thick mycelial density) even at the acidic state of the medium. The results of the present study suggest that L. swartzii is not $\mathrm{pH}$ sensitive, thereby, could grow within a wide range of $\mathrm{pH}$.

\subsection{Effect of Physical Factors}

After establishment of the optimum $\mathrm{pH}$ of $\mathrm{CWG}$, the effects of three physical factors, namely; illumination, temperature, and aeration on

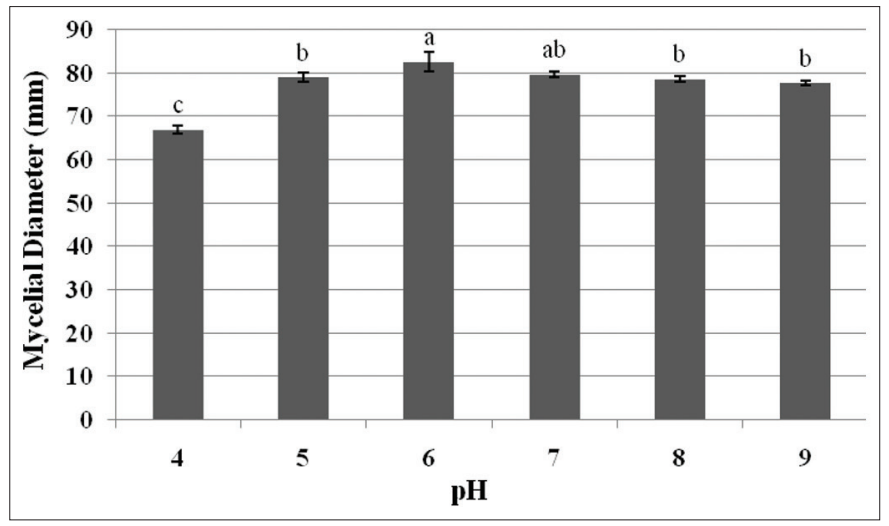

Figure 4: Mycelial growth diameter of Lentinus swartzii on Coconut water gulaman at different $\mathrm{pH}$ levels in 4 days of incubation. Means with the same letters of superscript are not significantly different according to Tukey's HSD $(P<0.05)$. the mycelial growth of $L$. swartzii were also studied. Although nonphotosynthetic, the presence or absence of light provides signal on the current status of the environment of mushroom, which is very essential for their survival. To determine the effect of illumination on the mycelial growth, cultures were incubated in artificial light and total dark conditions. Mycelia grown in total dark recorded higher mycelial growth diameter [Figure 6] and thicker and more cottony mycelia [Figure 7B] than those incubated in light condition [Figure 7A]. This positive response to total dark is similar to that of L. tigrinus, L. strigosus, Collybia reinakeana, L. tigrinus CLSU strain A, and G. lucidum strain B $[5,6,16,25]$. In contrast, light condition was suitable for the mycelial growth of $L$. sajor-caju and S. commune CLSU strain whereas the other nine mushrooms evaluated favorably grew in both light and dark conditions [16]. These reports prove that each strain and species of mushroom has distinctive illumination preference. In the case of $L$. swartzii, dark condition is the requirement. The inferior response of $L$. swartzii mycelia when exposed in light could probably be attributed to the light-associated stress factors brought by the artificial white light that resembles a mixture of wavelengths. Schumacher [26] stated that light may be associated with heat, leading to desiccation and osmotic stress. However, these can be counteracted by the production and accumulation of compatible solutes or osmoprotectants. For instance, in Botrytis cinerea, glycerol, and trehalose accumulate/ produce in response to osmotic and heat stresses, respectively [27,28]. This mechanism is probably similar to that of $L$. swartzii in response to light associated stress factors, which needs to be investigated in the future study.

Fungi can be classified as temperate, semi-temperate, and tropical species depending on their temperature requirements [29]. Another important physical factor that influences the mycelial growth of mushroom is temperature. Apparently, this is true in the case of L. swartzii [Figure 6]. Cultures incubated at $30^{\circ} \mathrm{C}$ recorded the highest mycelial growth diameter, while those incubated at $20^{\circ} \mathrm{C}$ showed suppressed mycelial growth. Both conditions produced thick mycelial growth [Figure 7C and D]. Accordingly, the maximum mycelial growth of $L$. swartzii can be attained when incubated at $30^{\circ} \mathrm{C}$, suggesting that this mushroom is a tropical species. The same finding was also reported in our previous works [5,6,16,24], which focused on the optimization of culture conditions of the Philippine mushrooms. This favorable response could be explained by the fact that these mushrooms are native in the Philippines and they are already adapted to the tropical conditions of the country. On the other hand, no mycelial growth was noted in those cultured at $10^{\circ} \mathrm{C}$. Similarly, no to slow mycelial growth was also observed in the different strains of $G$. lucidum when incubated at $15^{\circ} \mathrm{C}$ [30]. This inhibited growth could probably be attributed to impeded metabolic processes due to the denaturation of important enzymes.

The effect of aeration on the mycelial growth of $L$. swartzii was also determined. Culture plates were sealed with parafilm to deprive of direct oxygen, while the others were unsealed and exposed to aeration. The mycelial growth diameters of $L$. swartzii as affected by two aeration conditions in 4 days of incubation are presented in Figure 6. It can be seen that higher mycelial growth diameter was registered in sealed culture than in unsealed culture. $t$-test revealed that the difference was statistically significant. Cottony mycelia were observed in sealed culture while more compact mycelia were noted in unsealed culture [Figure 7F and G]. The results indicate that $L$. swartzii mycelia do not require aeration or direct exposure to oxygen. The same requirement was also noted in L. strigosus and G. lucidum [6,15]. Moreover, liquid culture, where agitation represents aeration, did not improve 

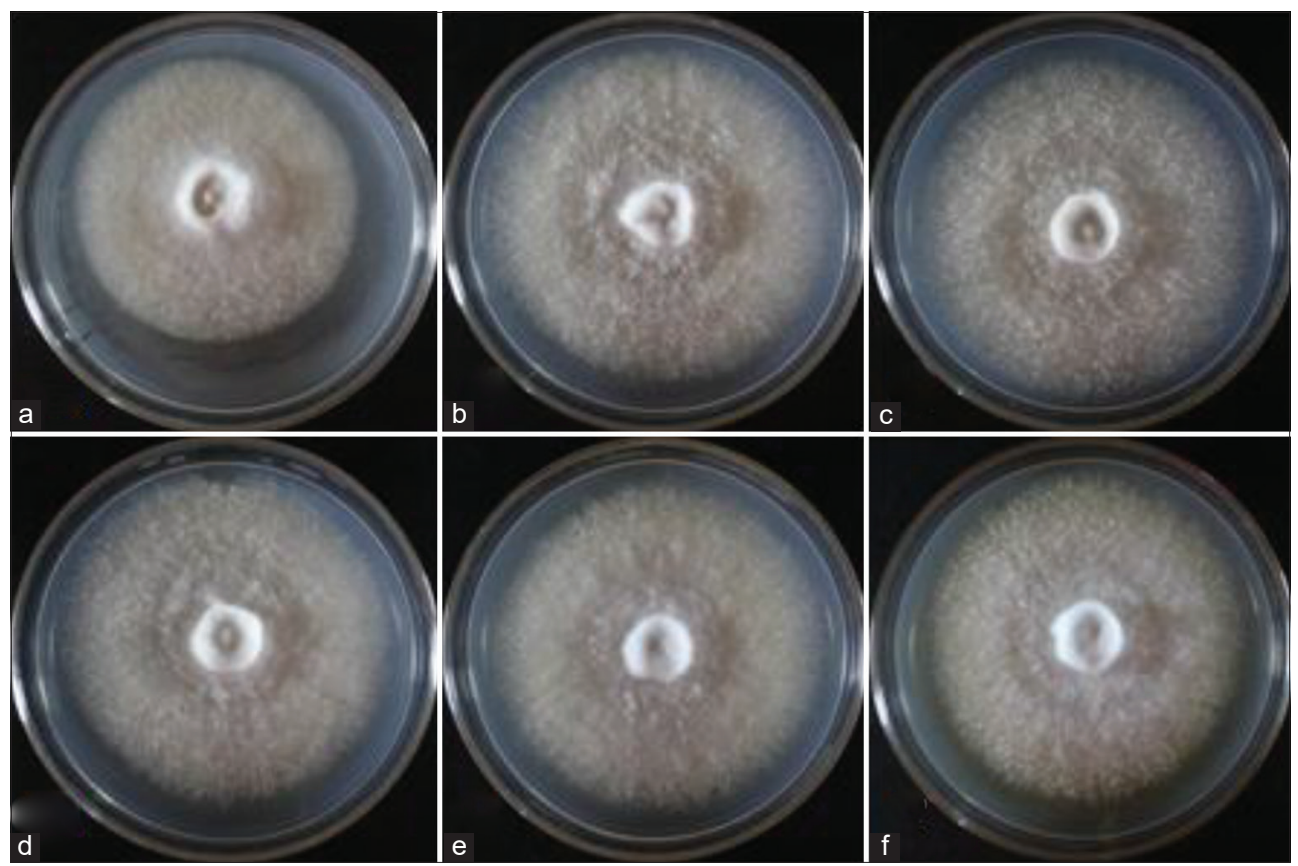

Figure 5: Mycelial growth of Lentinus swartzii on Coconut water gulaman at different $\mathrm{pH}$ levels: (a) $\mathrm{pH}$ 4; (b) $\mathrm{pH}$ 5; (c) $\mathrm{pH}$ 6; (d) $\mathrm{pH} 7$; (e) $\mathrm{pH}$ 8; and (f) $\mathrm{pH} 9$ on the $4^{\text {th }}$ day of incubation.

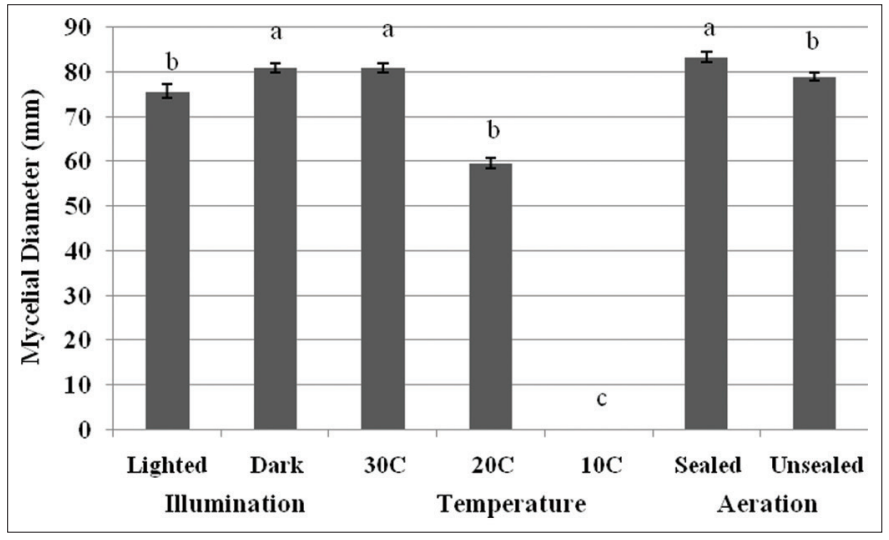

Figure 6: Mycelial growth diameter of Lentinus swartzii on Coconut water gulaman at $\mathrm{pH} 6$ as affected by illumination, temperature, and aeration conditions in 4 days of incubation. Means with the different letters of superscript within the same condition are significantly different according to Tukey's HSD and $t$-test $(P<0.05)$.

the mycelial biomass production of $P$. cystidiosus, $V$. volvacea, and S. commune [24].

Altogether, the present study established that better-quality mycelia growth of $L$. swartzii can be achieved when cultured in the dark, $30^{\circ} \mathrm{C}$, and sealed conditions - the optimal physical factors.

\subsection{Mycelial Growth on Grain Spawn}

In mushroom production, the suitable grain spawn material is also determined, in which the mycelia are mass produced to serve as planting material for the fruiting body production. Three grain spawning materials, namely; rice seeds, cracked corn seeds, and sorghum seeds were evaluated in this study, and the results are depicted in Figure 8. It can be seen that both rice seeds and cracked corn seeds recorded higher mycelial growth diameter when compared to sorghum seeds. In terms of mycelial density, all cultures produced thick mycelial growth [Figure 9]. This favorable mycelial response of $L$. swartzii to cracked corn seeds is the same to that of L. tigrinus and L. strigosus mycelia [5,7]. These previous works also explained that the favorable mycelial growth in cracked corn seeds as grain spawn was attributable to high moisture-holding capacity and exposed nutritious part. However, once fully ramified by mycelia, the granulated appearance of cracked corn was not maintained, thus, leading to a more laborious inoculation process of fruiting bags. Since rice seeds were also found favorable for mycelial growth and readily available in the locality, this material was used in the mass production of grain spawn.

\subsection{Fruiting Body Production on Rice Straw and Sawdust- based Substrate}

In nature, the emergence of the fruiting bodies is stimulated by the favorable conditions such as humidity, temperature, moisture of substrate, illumination, and even aeration. Aside from these physical factors, the quantity and type of substrate are also important requirements for the efficient growth of mushroom. The mentioned requirements must be emulated in the laboratory to generate production technology that could lead to the utilization of the wild mushroom for several purposes. In the case of L. swartzii, fruiting bodies were found growing on deadwood during early rainy season in the month of May. Since it is a wood-rotting mushroom, it could require dense lignocellulosic substrate to produce fruiting bodies. Hence, the present work investigated the mycelial growth and fruiting body production of $L$. swartzii in different formulations of rice straw and sawdust as the basal substrate. The number of days to full mycelial ramification and primordial initiation, weight of fruiting bodies, and biological efficiency of $L$. swartzii in different substrate formulations is presented in Table 1. Apparently, substrate formulations of 8:2 to $3: 7$ (rice straw:sawdust) recorded the shortest day to full mycelial ramification with a mean of 18 days. This did 


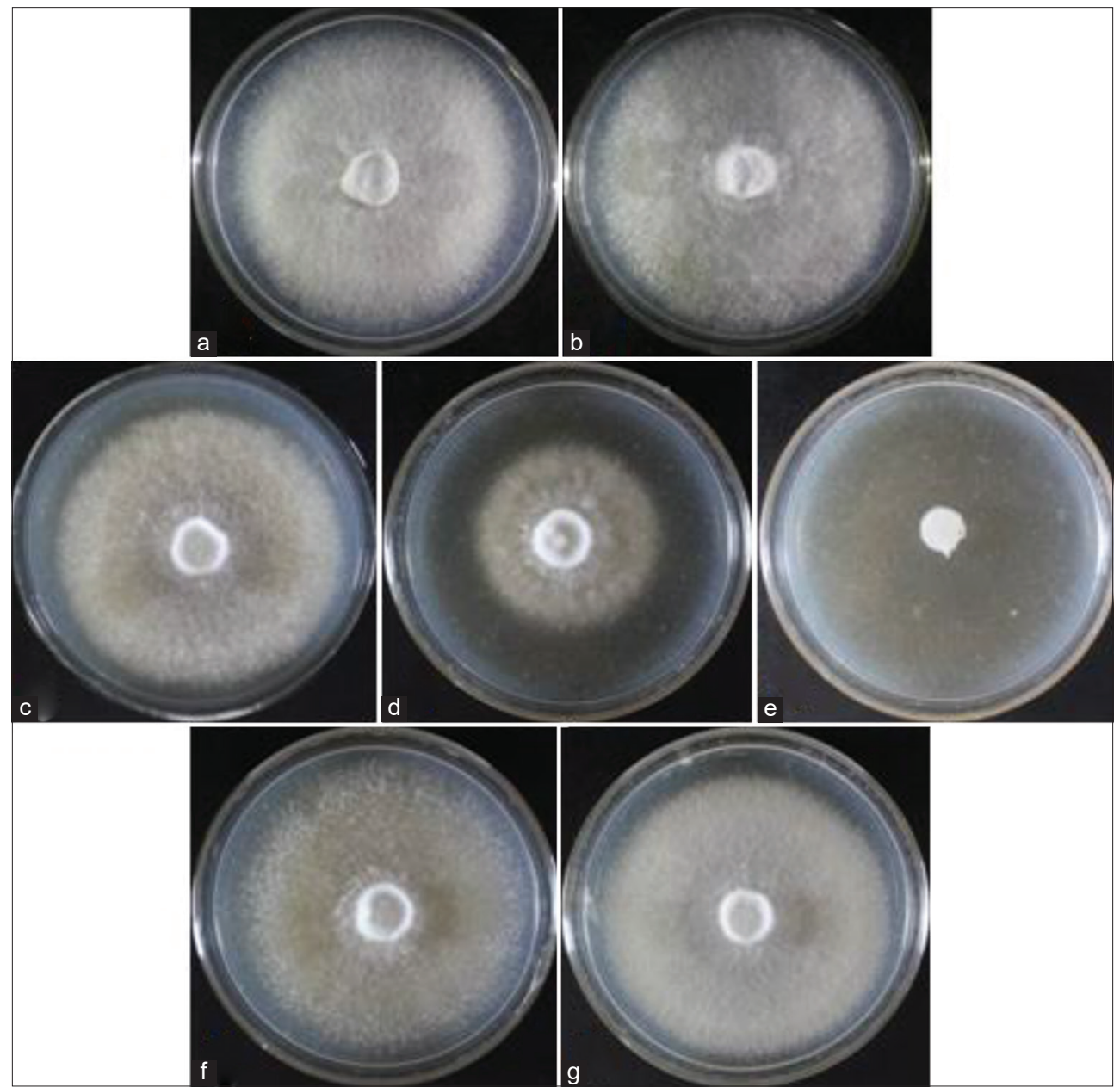

Figure 7: Mycelial growth of Lentinus swartzii on coconut water gulaman at $\mathrm{pH} 6$ as affected by illumination ([a] lighted and [b] dark), temperature ([c] $30^{\circ} \mathrm{C}$, $[\mathrm{d}] 20^{\circ} \mathrm{C}$, and $\left.[\mathrm{e}] 10^{\circ} \mathrm{C}\right]$ ) and aeration ([f] sealed and [g] unsealed) conditions on the $4^{\text {th }}$ day of incubation.

Table 1: Time periods of mycelial ramification and primordial initiation, weight of fruiting bodies, and biological efficiency of Lentinus swartzii on rice straw and sawdust based substrate.

\begin{tabular}{|c|c|c|c|c|}
\hline \multirow{2}{*}{$\begin{array}{l}\text { Substrate } \\
\text { (RS: SD) }\end{array}$} & \multicolumn{2}{|c|}{ Days to } & \multirow{2}{*}{$\begin{array}{l}\text { Wt. of fruit } \\
\text { body per } \\
\text { bag (g) }\end{array}$} & \multirow{2}{*}{$\begin{array}{c}\text { Biological } \\
\text { efficiency } \\
(\%)\end{array}$} \\
\hline & $\begin{array}{c}\text { Mycelial } \\
\text { ramification }\end{array}$ & $\begin{array}{c}\text { Primordial } \\
\text { initiation }\end{array}$ & & \\
\hline $10: 0$ & $20.67 \pm 0.58^{\mathrm{a}}$ & $36.33 \pm 1.15^{b}$ & $7.38 \pm 1.93^{\mathrm{d}}$ & $1.48 \pm 0.39^{\mathrm{d}}$ \\
\hline $9: 1$ & $18.67 \pm 0.58^{\mathrm{b}}$ & $35.67 \pm 1.53^{b}$ & $15.09 \pm 3.86^{\mathrm{c}}$ & $3.02 \pm 0.77^{\mathrm{c}}$ \\
\hline $8: 2$ & $18.00 \pm 0.00^{\mathrm{b}}$ & $36.00 \pm 1.73^{b}$ & $24.13 \pm 2.97^{b}$ & $4.83 \pm 0.59^{b}$ \\
\hline $7: 3$ & $18.00 \pm 0.00^{\mathrm{b}}$ & $34.33 \pm 0.58^{b}$ & $37.02 \pm 2.62^{\mathrm{a}}$ & $7.40 \pm 0.52^{\mathrm{a}}$ \\
\hline $6: 4$ & $18.00 \pm 0.00^{\mathrm{b}}$ & $36.33 \pm 1.15^{\mathrm{b}}$ & $22.17 \pm 2.30^{\mathrm{b}}$ & $4.43 \pm 0.46^{\mathrm{b}}$ \\
\hline $5: 5$ & $18.00 \pm 0.00^{\mathrm{b}}$ & $41.33 \pm 0.58^{\mathrm{a}}$ & $12.69 \pm 2.50^{\mathrm{cd}}$ & $2.54 \pm 0.50^{\text {cd }}$ \\
\hline $4: 6$ & $18.00 \pm 0.00^{\mathrm{b}}$ & $41.67 \pm 0.58^{\mathrm{a}}$ & $6.98 \pm 2.65^{\mathrm{d}}$ & $1.40 \pm 0.53^{\mathrm{d}}$ \\
\hline $3: 7$ & $18.00 \pm 0.00^{\mathrm{b}}$ & $41.33 \pm 0.58^{\mathrm{a}}$ & $7.05 \pm 1.20^{\mathrm{d}}$ & $1.41 \pm 0.24^{\mathrm{d}}$ \\
\hline $2: 8$ & $18.67 \pm 1.15^{\mathrm{b}}$ & NP & $0.00 \pm 0.00 \mathrm{e}$ & $0.00 \pm 0.00 \mathrm{e}$ \\
\hline $1: 9$ & $18.67 \pm 1.15^{\mathrm{b}}$ & NP & $0.00 \pm 0.00 \mathrm{e}$ & $0.00 \pm 0.00 \mathrm{e}$ \\
\hline $0: 10$ & $20.67 \pm 0.58^{\mathrm{a}}$ & NP & $0.00 \pm 0.00 \mathrm{e}$ & $0.00 \pm 0.00 \mathrm{e}$ \\
\hline
\end{tabular}

(RS: SD): Rice straw and sawdust ratio, NP: No primordia, Values are mean \pm SD. Means with the same letters of superscript are not significantly different according to Tukey's HSD $(P<0.05)$ not differ statistically from the time periods obtained in 9:1, 2:8, and 1:9. In contrast, both pure rice straw and pure sawdust registered the most extensive period for mycelial ramification (20.67 days). The durations obtained in the present work are close to the reported mycelial ramification periods (21-23.67 days) of L. strigosus [7] and are longer when compared to the mycelial ramification periods (7-9.2 days) of L. tigrinus [5].

After the full mycelial ramification, the next cultivation phase is the initiation of primordia. Among formulations, 7:3 had the shortest period for primordial initiation with a mean of 34.33 days. Surprisingly, this was statistically comparable to the formulations containing higher proportions of rice straw. This observation implies that $L$. swartzii has greater preference for rice straw. On the other hand, longer periods for primordial initiation were noted in 5:5, 4:6, and 3:7, while no primordia was observed in 2:8, 1:9, and pure sawdust. Although the conditions of the natural habitat were not perfectly replicated, the primordia (fruiting initials) of L. swartzii still successfully emerged, which strongly indicates that the substrates used and the environmental conditions in the growing house were also favorable for the development of its fruiting bodies. Accordingly, this mushroom can be cultivated in an artificial habitat. 
Given that the favorable conditions are maintained by providing proper cultural management, primordia develop into mature fruiting bodies. The fruiting bodies (pileus diameter range of 11.24$48.97 \mathrm{~mm}$ and stipe length range of $19.38-70.64 \mathrm{~mm}$ ) of $L$. swartzii

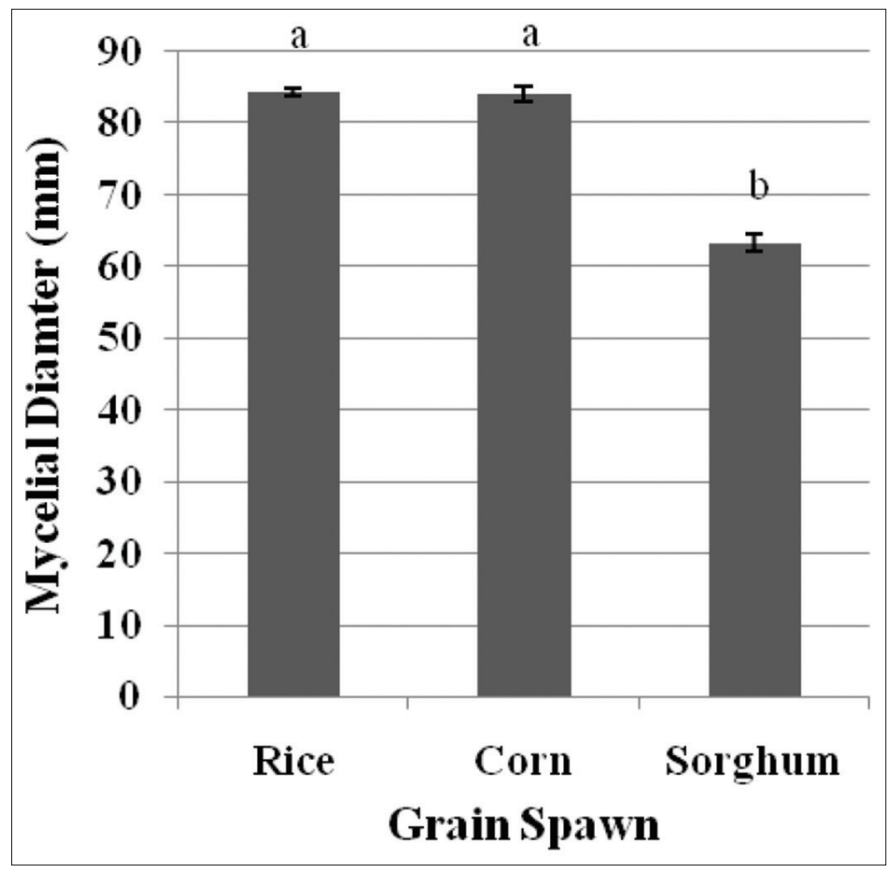

Figure 8: Mycelial growth diameter of Lentinus swartzii on the three spawning materials in 5 days of incubation. Means with the same letters of superscript are not significantly different according to Tukey's HSD $(P<0.05)$. were harvested and weighed to compute the percentage biological efficiency. Noticeably, the mean weight of fruiting bodies within 2-3 flushes significantly differed among the different substrate formulations. Among formulations, 7:3 produced the highest mean weight of fruiting bodies (37.02 g per bag) and correspondingly recorded the highest biological efficiency of $7.40 \%$. The fruiting bodies of L. swartzii growing on fruiting bags containing 7:3 formulation are shown in Figure 10. The bioefficiency obtained in the present study is almost the same with the maximum bioefficiencies of L. sajor-caju (7.2\%) [9] and L. squarrosulus (7.83\%) [8], but it is far lower compared with the reported bioefficiencies of L. tigrinus $(15.93 \%)$ when grown in eight parts of rice straw +2 parts of sawdust [5] and of L. strigosus $(20.97 \%)$ when cultivated in pure rice straw [7]. Therefore, it is imperative to evaluate production techniques to improve the biological efficiency of L. swartzii.

The previous work reported that enrichment of substrate using rice bran and corn grit improved the biological efficiency of L. strigosus from $19.03 \%$ to $32.79 \%$ for rice bran and $32.18 \%$ for corn grit [6]. De Leon et al. [31] also revealed that supplementation of $15 \%$ rice bran in eight parts of rice straw +2 parts of sawdust increased the bioefficiency of L. squarosulus from $7.83 \%$ to $18.00 \%$. However, cultivation of fruiting body under blue light-emitting diode is a useful technique in improving biological efficiency of L. tigrinus [32]. Moreover, application of voltages of 50 or $100 \mathrm{kV}$ stimulated the fruiting body formation and increased the accumulated yield of Lentinula edodes from $160 \mathrm{~g}$ to $320 \mathrm{~g}$ in four seasons of cultivation [33]. These above-mentioned techniques can be used for the improvement of fruiting body production of L. swartzii in the future studies.
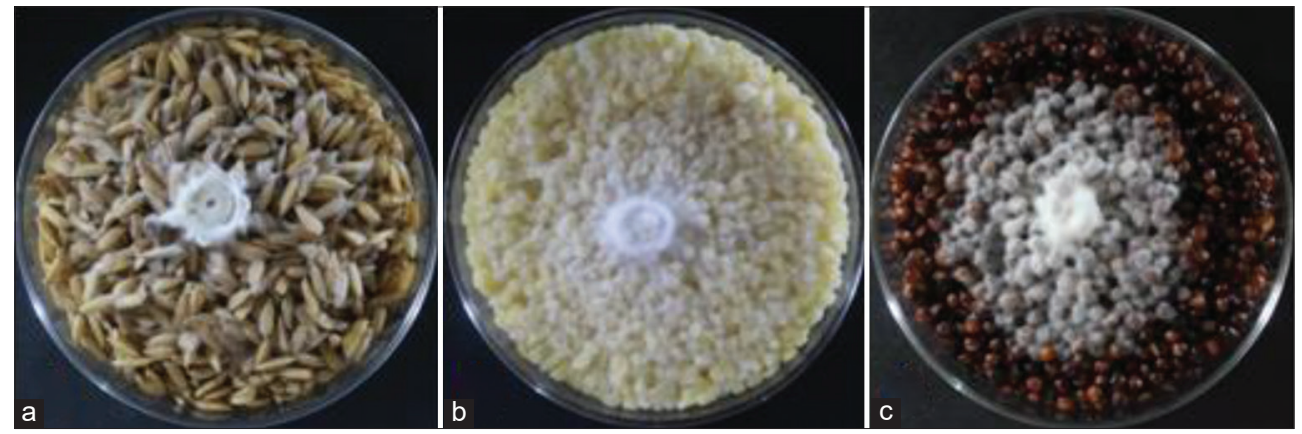

Figure 9: Mycelial growth of Lentinus swartzii on the three spawning materials: (a) rice seeds; (b) cracked corn; and (c) sorghum seeds on the $5^{\text {th }}$ day of incubation.
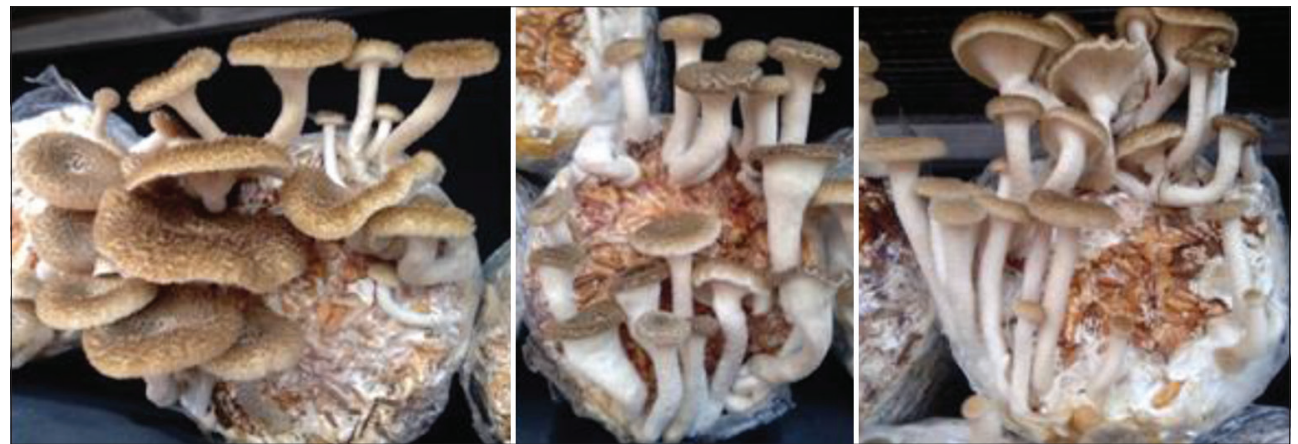

Figure 10: Fruiting bodies of Lentinus swartzii growing on fruiting bags containing 7:3 substrate formulation. 


\section{CONCLUSION}

This work provides the first report on the optimization of culture conditions for mycelia growth and fruiting body production of the newly rescued wild $L$. swartzii. The culture media, $\mathrm{pH}$, illumination, temperature, aeration, and grain spawn materials are important factors that significantly affect the mycelial growth of $L$. swartzii. The fruiting body, on the other hand, can be cultivated on substrate formulations with higher proportions of rice straw, suggesting the promising cultivation potential of $L$. swartzii. However, to enhance the biological efficiency of $L$. swartzii, experimentation on the enriched cultivation, application of shocking or physical stress, and optimization of climatic conditions for fruiting body production must be done. Furthermore, elucidation of chemical compositions and biological activities must also be taken into consideration to fully realize its position in the pharmaceutical industry.

\section{ACKNOWLEDGMENT}

The support from the Department of Science and Technology - Science Education Institute (DOST-SEI) in the Philippines is gratefully acknowledged. Mr. Rich Milton R. Dulay, a PhD Biology student of De La Salle University, is a recipient of scholarship under the Accelerated Science and Technology Human Resources Development Program (ASTHRDP) of DOST-SEI.

\section{AUTHOR CONTRIBUTIONS}

All authors made substantial contributions to conception and design, acquisition of data, or analysis and interpretation of data; took part in drafting the article or revising it critically for important intellectual content; agreed to submit to the current journal; gave final approval of the version to be published; and agree to be accountable for all aspects of the work. All the authors are eligible to be an author as per the international committee of medical journal editors (ICMJE) requirements/guidelines.

\section{CONFLICTS OF INTEREST}

The authors report no financial or any other conflicts of interest in this work.

\section{ETHICAL APPROVALS}

Not applicable.

\section{PUBLISHER'S NOTE}

This journal remains neutral with regard to jurisdictional claims in published institutional affiliation.

\section{REFERENCES}

1. Eguchi F, Kalaw SP, Dulay RM, Miyasawa N, Yoshimoto H, Seyama T, Reyes RG. Nutrient composition and functional activity of different stages in the fruiting body development of Philippine paddy straw mushroom, Volvariella volvacea (Bull.:Fr.) Sing. Adv Environ Biol 2015;9:54-65.

2. Patel Y, Naraian R, Singh VK. Medicinal properties of Pleurotus species (oyster mushroom): A review. World J Fungal Plant Biol 2012;3:1-12.

3. Nanglihan KE, Dulay RM, Kalaw SP. Myko-actives and functional activities of Philippine wild mushroom Trametes elegans. Int J Biosci 2018; $13: 402-8$.
4. Ahmed Z. Medicinal and antimicrobial properties of mushrooms. Sci J 2013;19:41-8.

5. Dulay RM, Kalaw SP, Reyes RG, Cabrera EC, Alfonso NF. Optimization of culture conditions for mycelial growth and basidiocarp production of Lentinus tigrinus (Bull.) Fr., a new record of domesticated wild edible mushroom in the Philippines. Philipp Agric Sci 2012;95:278-85.

6. Dulay RM, Garcia EJ. Optimization and enriched cultivation of Philippine (CLSU) strain of Lentinus strigosus (BIL1324). Biocatal Agric Biotechnol 2017;12:323-8.

7. Dulay RM, Rivera AG, Garcia EJB. Mycelial growth and basidiocarp production of wild hairy sawgill Lentinus strigosus, a new record of naturally occurring mushroom in the Philippines. Biocatal Agric Biotechnol 2017;10:242-6.

8. De Leon AM, Reyes RG, Dela Cruz TE. Lentinus squarrosulus and Polyporus grammocephalus: newly domesticated, wild edible macrofungi from the Philippines. Philipp Agric Sci 2013;96:411-8.

9. Cuevas MJ, Reyes R, Kalaw S. Biophysiology of Lentinus sajorсајu. J Trop Biol 2009;7:48.

10. Dulay RM, Arenas MC, Kalaw SP, Reyes RG, Cabrera EC. Proximate composition and functionality of the culinary-medicinal tiger sawgill mushroom, Lentinus tigrinus (Higher basidiomycetes), from the Philippines. Int J Med Mushrooms 2014;16:85-94.

11. Dulay RM, Kalaw SP, Reyes RG, Cabrera EC. Embryo-toxic and teratogenic effects of Philippine strain of Lentinus tigrinus (tiger sawgill basidiomycetes) extract on zebrafish (Danio rerio) embryos. Ann Biol Res 2014;5:9-14.

12. Dulay RM, Miranda LA, Malasaga JS, Kalaw SP, Reyes RG, Hou CT. Antioxidant and antibacterial activities of acetonitrile and hexane extracts of Lentinus tigrinus and Pleurotus djamour. Biocatal Agric Biotechnol 2017;9:141-4.

13. Dulay RM, Pamiloza DG. Proximate composition and bioactivities of hairy sawgill mushroom, Lentinus strigosus (BIL 1324) from the Philippines. Int J Biol Pharm Allied Sci 2018;7:361-9.

14. Eguchi F, Dulay RM, Kalaw SP, Yoshimoto H, Miyazawa N, Seyama T, Reyes RG. Antihypertensive activities of Philippine wild edible white rot fungus (Lentinus sajor-caju) in spontaneously hypertensive rats as models. Adv Environ Biol 2014;8:74-81.

15. Magday JC Jr., Bungihan ME, Dulay RM. Optimization of mycelial growth and cultivation of fruiting body of Philippine wild strain of Ganoderma lucidum. Curr Res Environ Appl Mycol 2014;4:162-72.

16. Kalaw SP, Alfonso DO, Dulay RM, De Leon AM, Undan JQ, Undan JR, et al. Optimization of culture conditions for secondary mycelial growth of wild edible mushrooms from selected areas in Central Luzon, Philippines. Curr Res Environ Appl Mycol 2016;6:277-87.

17. Dulay RM, Damaso EJ Jr. The first report on the successful rescue and domestication of Philippine wild mushroom Oudemansiella canarii (BIL 9137). Int J Biol Pharm Allied Sci 2017;6:2359-69.

18. Santoso U, Kubo K, Ota T, Tadokoro T, Maekawa A. Nutrient composition of kopyor coconuts (Cocos nucifera L.). Food Chem 1996;57:299-304.

19. Yong JWH, Ge L, Ng YF, Tan SN. The chemical composition and biological properties of coconut (Cocos nucifera L.) water. Molecules 2009;14:5144-64.

20. Borlingame B, Mouille B, Charrondiere R. Nutrients, bioactive non nutrients and anti-nutrients in potatoes. J Food Compos Anal 2009;22:494-502.

21. Jo WS, Kang MJ, Choi SY, Yoo YB, Seok SJ, Jung HY. Culture conditions for mycelial growth of Coriolus versicolor. Mycobiology 2010;38:195-202.

22. Jo WS, Rew YH, Choi SG, Seo GS, Sung JM, Uhm JY. The culture conditions for the mycelial growth of Phelinus spp. Mycobiology 2006;34:200-5. 
23. Kim SB, Kim SH, Lee KR, Shim JO, Lee MW, Shim MJ, et al. The optimal culture conditions for the mycelial growth of Oudemansiella radicata. Mycobiology 2005;33:230-4.

24. Dulay RM, Ray K, Hou CT. Optimization of liquid culture conditions of Philippine wild edible mushrooms as potential source of bioactive lipids. Biocatal Agric Biotechnol 2015;4:409-15.

25. Reyes R, Eguchi F, Iijima T, Higaki M. Collybia reinakeana, a wild edible mushroom from the forest of Puncan, Nueva Ecija, Philippines. Mushroom Sci Biotechnol 1997;15:99-102.

26. Schumacher J. How light affects the life of Botrytis. Fungal Genet Biol 2017;106:26-41.

27. Doehlemann G, Berndt P, Hahn M. Trehalose metabolism is important for heat stress tolerance and spore germination of Botrytis cinerea. Microbiology 2006;152 Pt 9:2625-34.

28. Dulermo T, Rascle C, Billon-Grand G, Gout E, Bligny R, Cotton P. Novel insights into mannitol metabolism in the fungal plant phatogen Botrytis cinerea. Biochem J 2010;427:323-32.

29. Lin Z. Grass (Juncao). In: Mushroom Grower's Handbook 1: Oyster Mushroom Cultivation. Seoul, Korea: Mush World-Heineart Inc.; 2004. p. 107-113.

30. Jayasinghe C, Imtiaj A, Hur H, Lee GW, Lee TS, Lee UY. Favorable culture conditions for mycelial growth of Korean strains of Ganoderma lucidum. Mycobiology 2008;36:28-33.

31. De Leon AM, Guinto LJ, De Ramos PDV, Kalaw SP. Enriched cultivation of Lentinus squarrosulus (Mont.) Singer: A newly domesticated wild edible mushroom in the Philippines. Mycosphere 2017;8:615-29.

32. Damaso EJ Jr, Dulay RM, Kalaw SP, Reyes RG. Effects of color light emitting diode (led) on the mycelial growth, fruiting body production, and antioxidant activity of Lentinus tigrinus. CLSU Int J Sci Technol 2018;3:9-16.

33. Takaki K, Yoshida K, Saito T, Kusaka T, Yamaguchi R, Takahashi K, Sakamoto Y. Effect of electrical stimulation on fruit body formation in cultivating mushrooms. Microorganisms 2014;2:58-72.

How to cite this article:
Dulay RMR, Cabrera EC, Kalaw SP, Reyes RG. Optimization of culture
conditions for mycelial growth and fruiting body production of naturally-
occurring Philippine mushroom Lentinus swartzii Berk. J App Biol Biotech.
2021;9(3):17-25.
DOI: $10.7324 / J A B B .2021 .9303$

